\title{
Avaliação da gestão do destino turístico Recife
}

Assessment of Recife tourism destination management

Evaluación de la gestión del destino turístico Recife

http://dx.doi.org/10.18472/cvt.16n2.2016.0986

Elizabete Regina de Santana 〈santana.ers@gmail.com >

Universidade Federal de Pernambuco (UFPE), Recife, PE, Brasil.

Nathália Körössy 〈nathaliakorossy@gmail.com >

Departamento de Hotelaria e Turismo da Universidade Federal de Pernambuco (UFPE), Recife, PE, Brasil.

Luciana Araújo de Holanda < luciana.holanda@ufpe.br >

Departamento de Hotelaria e Turismo da Universidade Federal de Pernambuco (UFPE), Recife, PE, Brasil.

CRONOLOGIA DO PROCESSO EDITORIAL

Recebimento do artigo: 17-out-2016

Aceite: 20 -ago-2016

FORMATO PARA CITAÇÃO DESTE ARTIGO

SANTANA, E. R de.; KÖRÖSSY, N.; HOLANDA, L. A. de. Avaliação da Gestão do Destino Turístico Recife. Caderno Virtual de Turismo. Rio de Janeiro, v. 16, n. 3, p. 30-42, dez. 2016.

REALIZAÇÃO

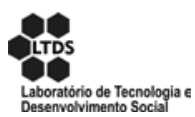

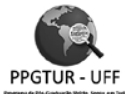

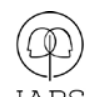

APOIO INSTITUCIONAL

EDIÇÃO

PATROCÍNIO

COPPE

UFR] 


\section{RESUMO}

Dada a competição entre cidades na atração dos visitantes, o ordenamento do desenvolvimento turístico e a promoção de ações de marketing revestem-se de crescente importância. Visando assumir papel de líder estratégico nesse processo, são criadas Organizações da Gestão de Destino (OGDs). No Brasil, as OGDs são majoritariamente públicas, normalmente secretarias vinculadas diretamente ao quadro do Poder Executivo. Visto que não há amplo conhecimento sobre a atuação de OGDs brasileiras em nível municipal, o presente trabalho busca suprir essa lacuna ao elaborar uma proposta metodológica para avaliação da gestão de destinos e aplicá-la no município de Recife. Para tanto, foram realizadas pesquisas bibliográfica, documental e de campo que consistiu em um estudo de caso qualitativo na Secretaria de Turismo e Lazer de Recife. Verificou-se que sua equipe técnica é qualificada; a gestão segue os princípios de descentralização, cooperação e corresponsabilidade; a maioria dos projetos foi realizada; há ferramentas de transparência pública; há grande dependência de recursos e falta uma marca turística da cidade. Conclui-se que a gestão turística do Recife atende parcialmente aos princípios de uma boa gestão de destino e precisa avançar em muitos aspectos.

Palavras-chave: Turismo. Gestão de Destino. Avaliação. Estudo de Caso. Recife.

\section{ABSTRACT}

As cities compete to attract visitors, destination management is an activity of growing importance on the local scale. So, Destination Management Organizations (DMO) are created with the aim to organize tourism development, promote marketing actions and be an strategic leader. Depending on the particularities of each country, a DMO may be public, private or shared responsibility. In Brazil, DMO are mostly public, usually Secretaries. Since there is no extensive knowledge about the performance of Brazilian DMO at the municipal level, this paper aims to fill this gap by developing a methodological proposal for the evaluation of destination management and applying it to the city of Recife. Therefore, bibliographical, documentary and field research were conducted. A qualitative case study in the Recife Secretary of Tourism and Leisure showed that its technical team is qualified, the management follows the principles of decentralization, cooperation and responsibility, most projects was carried out, there is public transparency tools however, there is heavy reliance on resources and lack a tourist brand of the city. Overall, Recife tourism management was evaluated as satisfactory.

Keywords: Tourism. Destination Management. Assessment. Case Study. Recife.

\section{RESUMEN}

Dada la competición entre ciudades en la atracción de los visitantes, la gestión de destinos se hace una actividad de creciente importancia en la escala local. Con el objetivo de ordenar el desarrollo turístico, promover acciones de marketing y asumir el papel de líder estratégico, son creadas Organizaciones de la Gestión de Destino (OGD) que pueden ser entidades públicas, privadas o de corresponsabilidad. En Brasil, las OGD son principalmente públicas, normalmente Secretarías vinculadas directamente al cuadro del Poder Ejecutivo. Dado que no existe un amplio conocimiento sobre el funcionamiento de OGD brasileñas a nivel municipal, este trabajo intenta llenar este vacío al mediante el desarrollo de una metodología para la evaluación de la gestión de destinos y su aplicación en la ciudad de Recife. Así, se realizó una investigación bibliográfica, documental y de campo que consistió en un estudio de caso cualitativo en la Secretaría de Turismo y Ocio de Recife. Los resultados mostraron que su equipo técnico está calificado, la gestión sigue los principios de la descentralización, cooperación y corresponsabilidad, la mayoría de los proyectos se llevó a cabo, hay herramientas de transparencia pública, sin embargo, hay una fuerte dependencia de los recursos y carecen de una marca turística de la ciudad. En general, la gestión del turismo de Recife fue evaluada como satisfactoria.

Palabras claves: Turismo. Gestión de Destinos. Evaluación. Estudio de Caso. Recife. 


\section{Introdução}

O turismo, sob o ponto de vista econômico, é uma importante fonte de receita para os países em desenvolvimento. Em 2015, a Organização Mundial de Turismo (OMT) registrou 1,2 bilhão de turistas viajando pelo mundo, tendo sido gerados US\$ 1,5 trilhão em receitas de exportação do turismo internacional (UNWTO, 2015). Diante dessas estatísticas, as cidades turísticas competem pela atração de visitantes para, com isso, promover o desenvolvimento turístico local. Desse modo, a criação de novos produtos e experiências, ações de qualificação dos recursos humanos e campanhas promocionais em mercados internacionais são alguns exemplos da atuação dos destinos na busca pela ampliação de seus fluxos turísticos receptores (CHIAS, 2007).

Nesse cenário de acirrada concorrência, uma gestão integrada do turismo torna-se essencial. Entendida como a administração coordenada de todos os elementos que formam uma destinação, a gestão de um destino é realizada por uma Organização de Gestão de Destino (OGD), em inglês Destination Management Organization (DMO) (UNWTO, 2007).

Devendo assumir a responsabilidade pelo planejamento das ações de desenvolvimento turístico local e pela coordenação dos esforços dos diversos stakeholders envolvidos na atividade, tais entidades são criadas com a finalidade de gerir o turismo em uma determinada localidade, coordenando os diferentes aspectos do destino, criando um ambiente adequado e estratégias de marketing capazes de atrair os visitantes potenciais (UNWTO, 2007). Assim, pode-se dizer que as OGDs são entidades gestoras que assumem um papel importante no planejamento e promoção da competitividade dos destinos turísticos.

Nem sempre os destinos serão geridos por OGDs apenas públicas. Em alguns países verifica-se casos em que a gestão é mista (de corresponsabilidade entre o setor público e o privado), ou, ainda, exclusivamente realizada pelo setor privado. Desse modo, percebe-se que o governo não é o único responsável pelo desenvolvimento turístico, sendo necessário contar com a participação do trade e de todos os atores envolvidos, direta ou indiretamente. Portanto, o modelo de gestão de destinos vai depender de cada localidade, de suas especificidades e do grau de cooperação entre os agentes públicos e privados.

No Brasil, as OGDs de nível local são majoritariamente de responsabilidade pública, normalmente Secretarias vinculadas diretamente ao quadro do Poder Executivo Municipal. Contudo, pouco se conhece sobre a situação atual dessas OGDs, tampouco existe um panorama geral sobre a gestão municipal do turismo no país. O conhecimento sobre a dinâmica de trabalho e estruturas organizacionais desses órgãos ainda é bastante escasso na literatura científica, apresentando-se de forma dispersa e fragmentada. Isso porque, de acordo com Solha (2005), a maioria dos estudos sobre políticas públicas de turismo aborda as questões nacionais da atividade turística.

Como contribuição a esta temática, o presente artigo versa sobre a avaliação da gestão do turismo na escala local, apresentando os resultados parciais de um projeto de pesquisa de caráter exploratório-descritivo, desenhado com o objetivo de elaborar uma proposta metodológica para avaliação da gestão pública dos quatro destinos turísticos indutores de Pernambuco (Recife, Olinda, Ipojuca e Fernando de Noronha) e da gestão turística feita pelo governo estadual de Pernambuco. Neste artigo, apresenta-se o estudo de caso da Secretaria de Turismo e Lazer de Recife (Pernambuco), para o recorte temporal de janeiro a setembro de 2013 . 


\section{Gestão do turismo na escala local}

No atual cenário de expansão dos fluxos turísticos internacionais e de concorrência entre destinos, não basta que uma localidade apenas possua uma vocação turística traduzida em recursos naturais e culturais. Mais do que isso, é fundamental a implementação de ações planejadas em uma perspectiva integrada (BENI, 2002, 2006; OMT, 2003; PETROCCHI, 2009; VALLS, 2006) capazes de transformar recursos em produtos turísticos (CHIAS, 2007).

Desse modo, a gestão turística de um destino torna-se elemento essencial ao desenvolvimento turístico em um mercado altamente competitivo. Para González (2008), a gestão de um destino turístico pode ser compreendida como um conjunto de ações que buscam o desenvolvimento turístico de uma localidade. De igual modo, a OMT (2007) entende que a gestão seja o processo de administração coordenada de todos os elementos que formam um destino, tais como atrativos, infraestrutura, acesso, marketing, preços, etc.

Com a finalidade, portanto, de realizar a gestão de um destino, ou seja, de geri-lo, são criadas entidades específicas para coordenar os aspectos relacionados ao turismo e promover um ambiente de cooperação entre os stakeholders (UNWTO, 2007). Entre as funções fundamentais para a eficiência e visibilidade do destino a cargo de uma OGD estão: o investimento e financiamento de melhorias do turismo local, a gestão dos recursos e serviços, a busca pela qualidade da experiência dos visitantes, o combate à sazonalidade, a produção de informação, comunicação, o estabelecimento de parcerias entre o setor público e privado, o marketing e promoção, bem como o monitoramento do destino (RITCHIE; CROUCH, 2003).

Essas funções podem ser exercidas em quaisquer escalas, a depender da escala do destino em questão. Assim, há OGD que atua em nível nacional, estadual, regional e local. Apesar do fomento da atividade turística em nível nacional ser de extrema importância, o nível local merece também destaque, pois é nele que são criados os empregos e é onde o turismo tem destaque (COSTA, 2004). É justamente por isso que a criação de OGD local deve ser incentivada e ampliada, de modo que atenda diretamente aos anseios de desenvolvimento turístico local.

Considerando a importância da atuação de OGD local na promoção da competitividade turística de um município, a Federación Española de Municipios y Provincias (2008) estabeleceu um conjunto de princípios a serem levados em consideração no processo de gestão local da atividade turística por uma OGD: eficácia, eficiência, cooperação, responsabilidade/justiça, transparência, tendência para uma maior estabilidade e autossuficiência financeira, orientação ao mercado e transversalidade, tal como explicados no Quadro 1.

Quadro 1 - Matriz com os princípios da gestão de destinos turísticos

\begin{tabular}{|c|c|}
\hline Eficácia & $\begin{array}{l}\text { Nível ideal de realização dos objetivos definidos pela política municipal de } \\
\text { turismo. }\end{array}$ \\
\hline Eficiência & Otimização do uso e gestão dos recursos (financeiros e humanos) disponíveis. \\
\hline Cooperação & $\begin{array}{l}\text { Envolvimento e cooperação dos agentes envolvidos (público e privado) são pré- } \\
\text { requisitos para o sucesso. }\end{array}$ \\
\hline $\begin{array}{l}\text { Responsabilidade/ } \\
\text { Igualdade }\end{array}$ & $\begin{array}{l}\text { Fórmulas e mecanismos que envolvam uma crescente responsabilidade dos } \\
\text { agentes privados, tanto na tomada de decisão como no esforço financeiro, } \\
\text { sempre sob o princípio da máxima igualdade. }\end{array}$ \\
\hline
\end{tabular}




\begin{tabular}{|l|l|}
\hline Transparência & $\begin{array}{l}\text { As entidades gestoras devem ser transparentes para a comunidade local em geral } \\
\text { e ao setor de turismo, em particular, tanto em seus objetivos (quais são e graus } \\
\text { de "performance" em sua realização), como em seus parâmetros financeiros. }\end{array}$ \\
\hline $\begin{array}{l}\text { Tendência para uma } \\
\text { maior estabilidade } \\
\text { e autossuficiência }\end{array}$ & $\begin{array}{l}\text { Os novos modelos devem conduzir a uma maior estabilidade e previsibilidade na } \\
\text { sua base financeira que permitam o horizonte de planejamento a médio e longo } \\
\text { prazo de seus planos de desempenho e uma maior autossuficiência financeira. }\end{array}$ \\
\hline $\begin{array}{l}\text { Orientação ao } \\
\text { mercado }\end{array}$ & $\begin{array}{l}\text { Uma vez que a principal função dos agentes de fomento e promoção turística } \\
\text { é de "vender” o destino, devem orientar-se para o mercado e ser competitivo. } \\
\text { Em nível operacional e executivo, devem ter um foco próprio de uma empresa } \\
\text { moderna, mas tendo em conta que são entidades de interesse público. }\end{array}$ \\
\hline Transversalidade & $\begin{array}{l}\text { Por natureza, o turismo é um setor transversal que afeta uma grande variedade } \\
\text { de atores (públicos e privados). A meta seria conseguir para esses entes a } \\
\text { máxima integração em seus participantes e órgãos de decisão. }\end{array}$ \\
\hline
\end{tabular}

Fonte: Adaptado de Federación Española de Municipios y Provincias (2008).

A busca pela adequação da atuação de uma OGD a esses princípios perpassa pelo envolvimento entre os diversos atores relacionados à atividade turística, sejam públicos ou privados. Nesse sentido, a governança, entendida como um processo de decisões entre setor público e privado que juntos vão tentar aprimorar a gestão e diminuir os conflitos que são causados pela atividade turística nos destinos (GONZÁLEZ, 2011), assume um papel fundamental.

Tais princípios representam um cenário ideal de atuação da OGD, consistindo, assim, em um norte a ser perseguido pela organização. Desse modo, devem ser aplicados não apenas na atuação da gestão, mas, também, como um mecanismo de avaliação da gestão. Nesse sentido, o monitoramento e avaliação da gestão de destinos ganham relevância visto que é mediante essas atividades que se pode verificar se a atuação da OGD na gestão do destino está atingindo ou não os resultados esperados. Trata-se de uma atividade essencial do processo de gestão e que deve ser realizada pela OGD que a realiza.

É justamente por considerar a relevância da atividade de avaliação que este artigo se propôs a realizar uma avaliação da gestão de um destino, a partir da análise da atuação de uma OGD local de natureza pública (Secretaria de Turismo e Lazer do Recife - Pernambuco).

\section{Procedimentos metodológicos}

De caráter exploratório-descritivo, este estudo busca não apenas descrever a dinâmica de uma OGD específica, mas também avaliar sua gestão turística. Com essa finalidade, realizou-se uma pesquisa bibliográfica, na qual foram consultados livros e artigos nacionais e internacionais, que forneceu as bases para a construção de um framework de análise.

A avaliação da gestão municipal do turismo de Recife fundamentou-se na seleção de quatro princípios defendidos pela Federación Española de Municipios y Provincias (2008) para a promoção de uma gestão eficiente do turismo: cooperação, transparência, tendência à estabilidade e autossuficiência financeira e orientação ao mercado. À luz desses princípios, organizou-se uma matriz referencial para a pesquisa de campo, a partir do desenho de um conjunto de categorias e respectivos indicadores para conduzir a coleta de dados (Quadro 2). 
Quadro 2 - Matriz referencial para pesquisa de campo

\begin{tabular}{|c|c|}
\hline CATEGORIA ANALISADA & INDICADORES \\
\hline Estrutura organizacional da OGD & $\begin{array}{l}\text { Organograma; Composição dos cargos; Atribuições dos } \\
\text { cargos; Orientação para o mercado. }\end{array}$ \\
\hline Dotação orçamentária & $\begin{array}{l}\text { Quantidade de recursos financeiros para investimento nas } \\
\text { ações (valores para o ano corrente - 2013); Origem dos } \\
\text { recursos; Formas de captação dos recursos externos (se } \\
\text { houver); Distribuição, percentual e critérios para as atividades } \\
\text { de cada setor do órgão; Estabilidade e autossuficiência } \\
\text { financeira. }\end{array}$ \\
\hline Estrutura física & $\begin{array}{l}\text { Existência de estrutura física adequada ao funcionamento } \\
\text { da gestão; Disponibilidade de tecnologias que auxiliam as } \\
\text { atividades de gestão. }\end{array}$ \\
\hline Natureza das ações realizadas & $\begin{array}{l}\text { Existência de Planos (Estratégico, Desenvolvimento, } \\
\text { Marketing); Programas; Projetos. }\end{array}$ \\
\hline $\begin{array}{l}\text { Monitoramento e avaliação da } \\
\text { gestão pela OGD }\end{array}$ & $\begin{array}{l}\text { Existência de mecanismos de monitoramento e avaliação dos } \\
\text { projetos. }\end{array}$ \\
\hline Transparência & $\begin{array}{l}\text { Existência de uma ferramenta de consulta pública sobre a } \\
\text { dotação e execução dos projetos. }\end{array}$ \\
\hline Governança & $\begin{array}{l}\text { Composição da instância; Atores da sociedade civil } \\
\text { organizada; Atores representantes do poder público; Ano de } \\
\text { criação e instalação da instância; Periodicidade das reuniões } \\
\text { ordinárias; Temas/Assuntos discutidos no recorte temporal; } \\
\text { Deliberações no período do recorte temporal da pesquisa; } \\
\text { Existência de mecanismos de transparência da instância de } \\
\text { governança; Cooperação/corresponsabilidade entre os atores. }\end{array}$ \\
\hline $\begin{array}{l}\text { Desafios para a gestão turística } \\
\text { do destino }\end{array}$ & Tipos de desafios. \\
\hline
\end{tabular}

Fonte: as autoras (2013).

Com base nessa matriz, foi planejado o protocolo de operacionalização da pesquisa documental e de campo, com a definição dos instrumentos de coleta e da técnica de análise dos dados. Assim, o processo teve início com buscas no site da Prefeitura da Cidade do Recife, no intuito de acessar notícias e publicações sobre os projetos e ações realizados pela Secretaria.

Em seguida, houve a etapa de pesquisa de campo que consistiu em um estudo de caso qualitativo na Secretaria de Turismo e Lazer do Recife. Os dados foram coletados por meio de entrevista semiestruturada com o gerente-geral de Planejamento e Gestão e o gerente de Projetos Turísticos, em agosto de 2013. O critério de seleção dos entrevistados foi acesso e disponibilidade. Não se conseguiu marcar entrevista com o secretário-executivo de Planejamento e Gestão.

Para analisar os dados obtidos na pesquisa documental e nas entrevistas, foi utilizada a técnica da análise de conteúdo (BARDIN, 2009). Seguiram-se as fases de pré-análise, exploração do material, tratamento dos resultados e interpretação, levando-se sempre em consideração a matriz de princípios da gestão de destinos turísticos (Quadro 1) e a matriz referencial para avaliação da gestão dos destinos (Quadro 2). Desse modo, foi possível avaliar a situação atual da gestão turística do Recife. 


\section{A Secretaria de Turismo e Lazer do Recife: breve caracterização}

A Secretaria de Turismo e Lazer do Recife foi instituída pela Lei n. 17.855, de 03 de janeiro de 2013, marcando o início do mandato da nova gestão municipal (2013-2017). Até 2005, a pasta era exclusivamente de Turismo, passando a incorporar o lazer desde então.

Sob o comando do secretário de Turismo e Lazer e de dois secretários-executivos (Lazer \& Turismo e Planejamento \& Gestão), a Secretaria de Turismo e Lazer contava com um quadro funcional de 71 funcionários, entre cargos efetivos e comissionados, conforme ilustrado no organograma (Figura 1). Cabe ressaltar que o órgão contava com mais de 70\% de turismólogos em seu quadro funcional, considerando a extrema importância da contribuição do Bacharel em Turismo ao fomento da atividade turística.

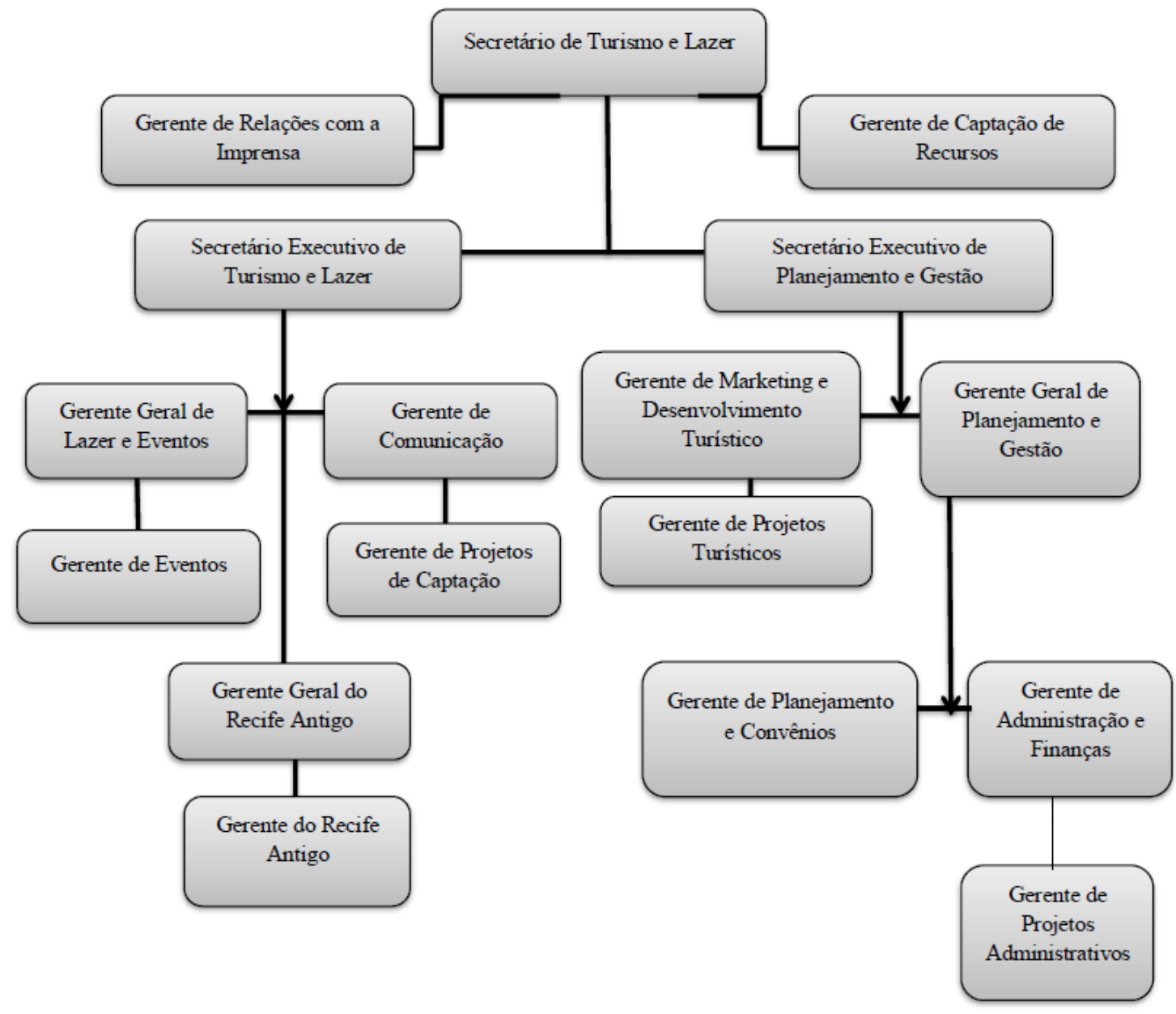

Figura 1 - Organograma da Secretaria de Turismo e Lazer do Recife Fonte: Pesquisa de campo (2013).

Os recursos para a pasta de Turismo e Lazer são provenientes do Ministério do Turismo (MTUR) e do Tesouro. Os recursos oriundos do Tesouro são captados através da Lei Orçamentária Anual (LOA), que apresenta todo o quantitativo de recursos disponíveis para o ano inteiro. Também há os recursos provenientes da celebração de convênios, mediante a captação em programas abertos no Sistema de Convênios (Siconv) do governo federal. Em 2013, a pasta de Turismo recebeu do Tesouro o valor de R 12.800 .000 para as ações e atividades do órgão. Nesse montante, estão inseridas as despesas com pessoal, investimentos e projetos. 
Com relação às ações realizadas pela Secretaria no primeiro semestre de 2013, verificou-se que o órgão elaborou Planos Operativos Anuais das ações a serem monitoradas pelo prefeito e Planos Operativos Anuais de ações internas a serem monitoradas pelo secretário. Além disso, a OGD dispunha de um plano estratégico de turismo, porém, disponível apenas para consulta interna, não tendo sido possível analisá-lo para a presente pesquisa. Nesse plano, segundo os entrevistados, constam não apenas a previsão das ações do novo governo, mas também as ações em continuidade planejadas pelo mandato anterior do Executivo.

Assim, nos primeiros meses do mandato da nova Secretaria, foram conduzidos cerca de 18 projetos nas áreas de marketing (campanhas promocionais, participação em eventos da área, etc.), desenvolvimento turístico (qualificação, sensibilização e sinalização) e lazer. Percebe-se, portanto, que a Secretaria de Turismo e Lazer vem realizando projetos e ações em diversos segmentos. Entre esses, oito foram voltados para o marketing, seis para o desenvolvimento do turismo e quatro para o lazer. Entre os projetos futuros, foram citadas ações relacionadas à promoção do Turismo de Base Comunitária (TBC) em algumas localidades da cidade, requalificação dos Centros de Atendimento ao Turista (CAT), qualificação da cadeia produtiva, entre outras. O monitoramento interno de todas essas ações é realizado todo mês na Secretaria de Turismo, com reuniões entre a equipe técnica e os gestores.

No que diz respeito à existência de ferramenta de consulta pública, verificou-se que não há um mecanismo específico mas, no site institucional da Prefeitura do Recife, no link do Portal da Transparência, são disponibilizadas informações sobre a dotação orçamentária para cada Secretaria e um demonstrativo das ações por programas do ano de 2013, ressaltando que nem todas as ações constam nessa ferramenta. No Portal da Transparência, constam também as receitas, as despesas, convênios, licitações e contratos, e demonstrativos contábeis e fiscais de todos os órgãos da Prefeitura do Recife. Ainda como um mecanismo de transparência das ações realizadas, pode-se citar o Relatório de Atividades da Secretaria de Turismo e Lazer 2013 que apresenta a atuação da Secretaria ao longo do ano.

Em relação à categoria da governança na gestão do turismo de Recife, identifica-se a existência do Conselho Municipal de Turismo (Conture), instituído em 1968 com a atribuição de formular e coordenar a política de turismo municipal. Essa instância de governança é vinculada à Secretaria de Turismo e Lazer do Recife, tendo como principais competências (de acordo com a Lei n. 9.927/68): a formulação de diretrizes básicas a serem obedecidas na política municipal, orientando convênios que venham a integrar em um plano geral de turismo; opinar na esfera do Poder Executivo, ou quando consultado pela Câmara Municipal do Recife, sobre anteprojeto de lei que se relacione com turismo; a proposição de procedimentos a serem adotados para a concessão de estímulos fiscais e financeiros; a declaração de centros e zonas prioritárias de interesse turístico na cidade do Recife e sua área metropolitana; entre outras.

Apesar de ser uma instância antiga, o Conture passou por períodos de inatividade entre 1979 e 1986 e de 1992 a 2007, quando foi reativado (HOLANDA; CARVALHO, 2008). Atualmente o Conture é composto por diversos atores, entre eles estão representantes do trade turístico, do governo estadual e do municipal. Há uma participação dos atores públicos e privados que tenham relação com a atividade turística para que possam discutir atividades para o setor.

O número atual de participantes do Conture é de 32 membros, sendo: 19 representantes do poder público e 13 da iniciativa privada. Atualmente, tais conselheiros atuam nas discussões sobre as ações da Secretaria, bem como na proposição de novas ações de turismo e lazer para a cidade. Com o acesso à Ata da primeira reunião do Conselho de 2013, foi possível constatar que $68 \%$ dos membros participaram, o 
que demonstra interesse na gestão participativa. Também, verificou-se que a pauta da reunião trouxe o debate sobre as ações realizadas e que serão executadas.

Por fim, cabe comentar sobre os principais desafios a serem enfrentados pela OGD na gestão do turismo de Recife, sob a óptica dos entrevistados. Considerando que o período analisado pela pesquisa de campo correspondeu ao início do mandato da nova equipe gestora, os entrevistados apontaram como grande desafio a continuidade das ações planejadas do mandato anterior e o planejamento das novas ações para a pasta durante os quatro anos de mandato até 2017.

Foi mencionada também a dificuldade na organização interna da OGD que demanda melhorias na estrutura física de funcionamento do órgão. A dificuldade em conseguir levar a cabo aquilo que foi planejado "no papel", mediante a captação de recursos, também foi mencionada. Outro fator que, na opinião dos gestores, atrapalha a implementação das ações planejadas consiste na burocracia inerente ao aparelhamento do Estado que implica em longos períodos de tempo com o processo de licitações. Trata-se de uma questão inerente à gestão pública.

A captação de recursos também foi citada como um desafio à gestão do turismo de Recife, bem como a atração da demanda turística para a cidade. Segundo um entrevistado, "a demanda ainda é baixa para a potencialidade da cidade". Desse modo, considera-se que seja importante incrementar ações promocionais e de segmentação do público.

Percebe-se, pois, a intenção de captar uma demanda diferenciada para o município, mas para isso é necessário direcionar as ações de promoção e marketing, além de preparar a cidade para receber esse público. Como a gestão ainda é recente, muitos desafios irão surgir ao longo dos quatro anos de mandato da OGD.

\section{Avaliação da gestão turística do Recife}

Levando em consideração os princípios defendidos pela Federación Española de Municipios e Provincias (2008) e a realidade da Secretaria de Turismo e Lazer de Recife descrita no estudo de caso, propõe-se avaliar a gestão turística do Recife a partir do exame da atuação dessa OGD do âmbito público.

No que diz respeito ao princípio da cooperação e corresponsabilidade, observa-se a existência de um Conselho Municipal de Turismo, que integra o setor público e privado em prol do turismo local. Considerando ser indispensável a participação das entidades privadas na gestão de um destino, nas reuniões do Conture os dois setores discutem as estratégias para o desenvolvimento do turismo. Com a cooperação entre os responsáveis pela atividade turística, fica mais fácil gerir e desenvolver o turismo na localidade.

Nessa instância de governança, verificou-se que as ações de gestão da OGD são debatidas em conjunto com o setor privado, ficando a cargo de cada órgão enviar seus representantes para participarem das suas reuniões. É função da OGD articular e envolver o trade na gestão da atividade turística.

É indispensável que haja um compartilhamento das responsabilidades entre o setor público e privado. A contribuição deve ser igual para ambos os setores, tanto nas decisões quanto no esforço financeiro. Apesar da pesquisa de campo não ter acompanhado as reuniões do Conture, pode-se verificar, sob a óptica dos entrevistados, que o poder público acaba por assumir a maior responsabilidade (técnica e financeira) na condução das ações para o setor. Desse modo, apesar de existir um espaço para cooperação e compartilhamento das responsabilidades por meio da atuação do Conture, na realidade de Recife ainda é o setor público quem assume o desenvolvimento e implementação das ações. 
Em relação à transparência, verificou-se a existência de um portal de consulta pública na página institucional da Prefeitura do Recife, onde é disponibilizado o orçamento anual para cada Secretaria. Nesse orçamento, é discriminado como será utilizado o valor que cabe ao órgão de turismo. Na pesquisa realizada nessa ferramenta, verificou-se que nem todos os programas e ações estão disponíveis.

Cabe ressaltar ainda como um mecanismo de transparência, o Relatório de Atividades da Secretaria de Turismo e Lazer (PREFEITURA DO RECIFE, 2013) que foi disponibilizado no primeiro semestre de 2013. De acordo com o próprio relatório, o objetivo do documento é proporcionar uma maior transparência à sociedade, demonstrando (ao menos no discurso) uma preocupação do órgão com o quesito transparência. Nesse documento, são destacados os principais projetos, ações e atividades do órgão em seus diferentes campos de atuação. Apresenta-se nele um detalhamento de cada ação executada e prevista, a forma de captar os recursos, o nome dos funcionários envolvidos, o cargo de cada um deles, as qualificações e as reuniões realizadas com os funcionários.

Contudo, a falta de divulgação do Relatório faz com que as pessoas não saibam da existência desse documento. Considerando que a população tem direito de saber quais as ações foram e serão realizadas na cidade do Recife e, portanto, a necessidade de se divulgar amplamente a existência do documento, sugere-se que o órgão também disponibilize esse documento em uma versão on-line e divulgue essa ferramenta de transparência para a sociedade, estudantes de turismo e pesquisadores, já que o intuito é proporcionar transparência.

O terceiro princípio diz respeito a uma maior tendência à estabilidade e autossuficiência financeira da OGD, ressaltando a importância do órgão ser mais independente quanto às suas arrecadações e fontes de recursos. No entanto, constatou-se que há uma grande dependência tanto dos recursos internos da Prefeitura do Recife quanto externos. Na pesquisa, verificou-se que, para pôr seus projetos em prática, a Secretaria de Turismo e Lazer de Recife precisa captar recursos internos e externos, e no caso de não haver a captação dos recursos financeiros, os projetos não são implementados.

Por não ter uma independência financeira, muitas ações demoram a se concretizar, já que dependem do estabelecimento de convênios e questões burocráticas. A demora na captação de recursos ocasiona uma quebra no desenvolvimento do turismo, deixando os visitantes e moradores insatisfeitos com a atividade turística local. Trata-se da realidade de qualquer OGD, de caráter público, no país. Uma possível alternativa seria a implementação de uma estrutura mista, com participação jurídica tanto do setor público quanto do privado, tal como é utilizado na gestão local do turismo de países como França e Espanha, por exemplo.

O último princípio avaliado se refere à orientação ao mercado. Observou-se que há uma grande participação do órgão em feiras de turismo, eventos e workshops voltados para jornalistas e agentes de viagens. Nesses eventos, são realizadas ações de marketing como a distribuição de materiais promocionais, demonstração do frevo e da gastronomia local. Porém, para posicionar o Recife no mercado nacional e internacional é imprescindível a criação de uma marca que identifique o destino.

Com uma marca definida, o destino fica mais competitivo e consegue atrair uma maior demanda para a localidade. É importante que os gestores tenham uma visão moderna e criem uma marca para posicionar o Recife enquanto destino competitivo, no estado, no Brasil e no mundo. Sabe-se que saem e entram 
equipes de gestão a cada mandato do Executivo municipal e por questões políticas não é definida uma marca que identifique o destino Recife'.

Face ao exposto, levando em consideração os princípios apresentados, pode-se concluir que a gestão turística do Recife, conduzida pela sua Secretaria de Turismo e Lazer, vinculada ao quadro do governo municipal, dentro do recorte temporal desta pesquisa, atende, ao menos parcialmente, aos princípios analisados. Vale ressaltar que por ser uma organização pública, nem tudo acontece rápido e há sempre dificuldades que impedem uma gestão mais eficiente.

\section{Considerações Finais}

Partindo da ideia que uma OGD deva exercer o papel de orientadora da atividade turística local, articulando com os diversos stakeholders (empresários, sociedade civil organizada, etc.) a política de turismo e compartilhando as responsabilidades entre o setor público e privado, o presente trabalho se propôs avaliar a gestão turística do Recife, a partir da análise da atuação da sua Secretaria de Turismo e Lazer, instituída no início de 2013.

De acordo com a matriz referencial de princípios da gestão de destinos turísticos, avalia-se que a gestão conduzida pela OGD:

- Atende parcialmente ao princípio da cooperação e corresponsabilidade, ao ter um Conselho Municipal de Turismo (Conture) com agentes públicos e privados trabalhando juntos para fortalecer o turismo local, contribuindo para o processo de gestão participativa do destino. Contudo, percebeu-se que ao poder público sempre tem cabido a maior responsabilidade na implementação e financiamento das ações de desenvolvimento turístico.

- Atende parcialmente ao princípio da transparência pública. Apesar de existir o Portal da Transparência e o Relatório de Atividades da Secretaria de Turismo e Lazer, nota-se que tais ferramentas ainda precisam de maior detalhamento de informações e de maior alcance no acesso dos cidadãos. Assim, seria interessante a criação de um portal de transparência exclusivo da Secretaria de Turismo e Lazer de Recife que contenha não apenas a prestação de contas do órgão, mas, principalmente, que divulgue as ações realizadas, em andamento e previstas e que seja um canal de interação com os stakeholders.

- Não atende ao princípio da tendência a maior estabilidade e autossuficiência financeira, visto que há uma grande dependência dos recursos internos à Prefeitura e externos, como do Ministério do Turismo. Em um eventual cenário de dificuldade dessas fontes, ficaria inviável a execução dos projetos elaborados pela Secretaria. Como sugestão, seria interessante fazer um benchmarking entre os países e cidades que tiveram êxito ao utilizar o modelo de gestão mista, com diferentes tipos de arrecadação e captação de recursos.

- Atende parcialmente ao princípio da orientação ao mercado. Percebeu-se que apesar de haver uma clara participação da OGD em feiras de turismo, eventos e workshops levando o material pro-

\footnotetext{
1 Em 1993, a Secretaria de Desenvolvimento Econômico, Turismo e Esportes desenvolveu um trabalho com uma agência de propaganda e publicidade criando a marca "Coquinho Alto Astral", que seria o símbolo da cidade visando construir uma imagem positiva através do slogan "Recife Alto Astral". Pela primeira vez se instituiu uma marca da cidade aprovada por lei. No entanto, por questões partidárias, não se deu continuidade a esse importante aspecto da promoção turística de um destino turístico (HOLANDA, 2003).
} 
mocional da cidade, nota-se que o destino ainda não possui uma marca turística. É imprescindível que a gestão defina uma marca para o turismo do Recife que o posicione nos mercados nacional e internacional. Além disso, é importante a criação de uma página exclusiva para promover o turismo de Recife que seja atrativa, moderna, interativa e em várias línguas, com fotos dos atrativos, eventos, hotéis, restaurantes, mapa, telefones úteis, participação em feiras e eventos e as ações realizadas pela gestão turística, além da elaboração de um aplicativo para smartphones.

Ainda se verificou, no caso da Secretaria de Turismo e Lazer de Recife, a existência de uma equipe técnica qualificada e especializada, o que é imprescindível para a condução das atividades da gestão. Contudo, a estrutura física de trabalho, na opinião dos entrevistados, ainda pode ser considerada um entrave ao adequado funcionamento da OGD. Ao identificar as ações em curso e previstas, constatou-se um considerável número de projetos em implementação, embora tenha-se verificado como desafio a constante dificuldade na captação de recursos financeiros, demonstrando que o órgão não dispõe de autossuficiência financeira.

Assim, com base no exposto, conclui-se que a gestão turística de Recife, empreendida pela Secretaria de Turismo e Lazer, ainda precisa avançar na busca por melhorias na adequação de suas práticas aos princípios norteadores desta pesquisa. Face aos resultados apresentados, esta pesquisa pode ser útil como um instrumento de consulta aos gestores da OGD ao apresentar um breve diagnóstico da situação atual da entidade e uma avaliação da atuação da OGD no processo de gestão do destino, fornecendo-se assim um norte referencial do que seria uma atuação ideal.

\section{Referências}

BARDIN, L. Análise de conteúdo. 4. ed. Lisboa: Edições 70, 2009.

BENI, M. C. Análise estrutural do turismo. 7. ed. rev. São Paulo: Senac, 2002.

Política e planejamento do turismo no Brasil. São Paulo: Aleph, 2006.

CHIAS, J. Turismo, o negócio da felicidade: desenvolvimento e marketing turístico de países, regiões, lugares e cidades. São Paulo: Editora Senac, São Paulo, 2007.

COSTA, C. Turismo e poder local. In: CONGRESSO ASSOCIAÇÃO NACIONAL DE MUNICÍPIOS PORTUGUESES, 14, 2004, Actas... Funchal, Portugal, 2004.

FEDERACIÓN ESPANÕLA DE MUNICIPIOS Y PROVINCIAS. Modelos de gestión turística local: princípios y praticas. Madrid: 2008.

GONZÁLEZ, M. V. La política turística: una arena de acción autónoma. Cuadernos de Turismo, n. 27, 2011, p. 953-969.

Gestión de destinos: gobernabilidad del turismo o gobernanza del destino? In: SIMPOSIO INTERNACIONAL DE TURISMO Y OCIO ESADE, 17, 2008, Anales... Barcelona, España, 2008. Disponível em: 〈http://www.esade.edu/cedit/pdfs/papers/pdf5.pdf〉. Acesso em: 23 ago. 2013.

HOLANDA, L. A. Formação e institucionalização do campo organizacional do turismo no Recife-PE. 208 f. 2003. Dissertação (Mestrado em Administração). Universidade Federal de Pernambuco. Recife: UFPE, 2003. 
.; CARVALHO, A. R. M. Conselho Municipal de Turismo: para quê? para quem? In: SEMINÁRIO DA ASSOCIAÇÃO DOS PROGRAMAS DE PÓS-GRADUAÇÃO EM TURISMO, 5, 2008, Anais... Belo Horizonte, ANPTUR, 2008.

LICKORISCH, L.; JENKINS, C. Introdução ao Turismo. Rio de Janeiro: Campus, 2000.

ORGANIZAÇÃO MUNDIAL DO TURISMO. Turismo internacional: uma perspectiva global. 2. ed. Porto Alegre: Bookman, 2003.

PETROCCHI, M. Turismo: planejamento e gestão. São Paulo: Futura, 2009.

PREFEITURA DO RECIFE. Conture reinicia discussões com o trade turístico. Disponível em: 〈http:// www2.recife.pe.gov.br/conture-inicia-discussoes-com-trade-turistico〉. Acesso em: 22 ago. 2013.

Portal da Transparência. Disponível em: 〈http://portaltransparencia.recife.pe.gov.br〉. Acesso em: 22 ago. 2013.

Relatório de Atividades da Secretaria de Turismo e Lazer. Secretaria de Turismo e Lazer, 2013.

RITCHIE, J. R. B.; CROUCH, G. I. The competitive destination: a sustainable tourism perspective. Estados Unidos: CAB International, 2003.

SOLHA, K. T. Órgãos públicos estaduais e o desenvolvimento do turismo no Brasil. 178 f. 2004. Tese. (Doutorado em Ciências da Comunicação). Universidade de São Paulo. São Paulo: USP, 2004.

UNITED NATIONS WORLD TourISM ORGANIZATION. A Pratical Guide to Tourism Destination Management. Madrid: UNWTO, 2007. Disponível em: 〈http://www.tdmszovetseg.eu/files/_tdmsz/ download_files/12/unwto_practicalguide.pdf〉. Acesso em: 7 jan. 2013.

UNWTO Tourism Highlights: 2015 Edition. Madri, Spain: UNWTO, 2015. Disponível em: 〈http://www.e-unwto.org/doi/pdf/10.18111/9789284416899〉. Acesso em: 18 jun. 2016.

VALLS, J. F. Gestão integral de destinos turísticos sustentáveis. Rio de Janeiro: FGV, 2006. 